Metallophysics and Advanced Technologies

Металофіз. новітні технол.

Metallofiz. Noveishie Tekhnol.

2021 , vol. 43, No. 9, pp. 1207-1224

https://doi.org/10.15407/mfint.43.09.1207

Reprints available directly from the publisher
(C) 2021 G. V. Kurdyumov Institute for Metal Physics, National Academy of Sciences of Ukraine Published by license under

the G. V. Kurdyumov Institute for Metal PhysicsN.A.S. of Ukraine Publishers imprint.

PACSnumbers: 61.25.Mv, 61.43.Bn, 64.60.My, 64.70.dg, 81.07.Bc, 81.10.Fq, 81.30.Hd

\title{
Kinetics of Competitive Crystallization of Lanthanum upon Rapid Cooling of the Melt
}

\author{
A. B. Lysenko, I. V. Zagorulko*, T. V. Kalinina, \\ and O. A. Zadorozhnia \\ Dniprovsk State Technical University, \\ 2 Dniprobudivska Str., \\ UA-51918 Kamianske, Ukraine \\ ${ }^{*}$ G. V. Kurdyumov Institute for Metal Physics, NAS of Ukraine, \\ 36 Academician Vernadsky Blvd., \\ UA-03142 Kyiv, Ukraine
}

Using a mathematical model of competitive crystallization of polymorphic metals a numerical analysis of formation kinetics of the metastable polytype of lanthanum ( $\mu$-La), which is fixed in the products of quenching from the liquid state in a mixture with crystallization of the equilibrium f.c.c. $\beta$ modification, is carried out. The interval of rapidly quenched foils thicknesses is determined, within which the metastable $\mu$-phase is formed in quantities sufficient for experimental detection. The calculated data agree with the results of X-ray phase analysis at the physically correct value of the free parameter of the model $\Delta G_{\mu \beta}=5 \mathrm{~J} / \mathrm{mol}$, which has the meaning of the degree of metastability of $\mu$-La.

Key words: melt quenching of lanthanum, competitive crystallization, metastable polytype, formation kinetics.

3 використанням математичної моделі конкурентної кристалізації поліморфних металів виконано чисельний аналіз кінетики формування метастабільного політипу лантану ( $\mu$-La), який фіксується у продуктах гартування з рідкого стану у суміші з рівноважною $\beta$-модифікацією. Визначено інтервал товщин швидкозагартованих фольг, у межах якого метастабільна $\mu$-фаза утворюється у кількостях, достатніх для експериментального

Corresponding author: Oleksandr Borysovych Lysenko

E-mail: ablysenko@ukr.net

Citation: A. B. Lysenko, I. V. Zagorulko, T. V. Kalinina, and O. A. Zadorozhnia, Kinetics of Competitive Crystallization of Lanthanum upon Rapid Cooling of the Melt, Metallofiz. Noveishie Tekhnol., 43, No. 9: 1207-1224(2021),

DOI: $10.15407 /$ mfint.43.09.1207. 
виявлення. Досягнуто узгодження розрахункових даних та результатів рентгенофазового аналізу за фізично коректного значення вільного параметра моделі $\Delta G_{\mu \beta}=5$ Дж/моль, що має сенс ступеня метастабільності $\mu$-La.

Ключові слова: гартування розтопу лантану, конкурентна кристалізація, метастабільний політип, кінетика формування.

(Received July 2, 2021)

\section{INTRODUCTION}

According to the data of [1-4], upon quenching from the liquid state (QLS) of light rare earth elements of the cerium group (La, Ce, Pr, Nd) with cooling rates $v$ above $\sim 10^{5} \mathrm{~K} / \mathrm{s}$ in the structure of rapidly quenched samples, along with the equilibrium close-packed modification, the metastable $\mu$-modification of metals is fixed by crystallizing from a melt under nonequilibrium cooling conditions. It has a sevenlayer hexagonal compact $7 \mathrm{R}$ lattice with the sequence of stacking close-packed atomic layers ABCABAC.... The formation of the 7R lattice is explained by the saturation of the base modification with periodically located packing defects (PD) that arise under conditions of rapid crystal growth in a supercooled melt.

It is shown that the high predisposition of metals of the studied group to the formation of $7 \mathrm{R}$-structures is due to the following reasons:

- narrow (59-161) K temperature range of stability of hightemperature modifications with a b.c.c. lattice [5], crystallizing from the melt under conditions close to equilibrium;

- the possibility of supercooling the melt outside the specified interval, which makes the crystallization process competitive;

- a record low energy level of packing defects (for Ce-5.10 $\mathrm{J} / \mathrm{m}^{2}$ [6]), which increases the probability of their multiple formation under the influence of various types of treatment, including quenching from a liquid state [7];

- the polytypism of light lanthanides, i.e. the presence of several close-packed modifications differing only in the total number and sequence of atomic layers [8].

In Figure 1 shows the schemes of the formation of multilayer closepacked structures of two different types by saturation with packing defects in the $\beta$-La f.c.c. lattice $[1,2]$. As seen from Fig. 1, $a$, when packing defects are introduced through three atomic layers, the f.c.c. lattice is transformed into a four-layer (ABAC...) lattice d.h.c. (double hexagonal compact) of the equilibrium $\alpha$-modification. At a lower concentration of PDs, which are repeated through 6 atomic layers, the sequence of alternating close-packed $\mathrm{ABC}$... planes characteristic of the f.c.c. lattice is transformed into the $\mathrm{ABCABAC}$... sequence correspond- 
ing to the 7R-lattice of the metastable $\mu$-La modification (Fig. 1, b).

Comparative analysis presented in Fig. 1 of rearrangement schemes of the basic f.c.c. lattice of $\beta$-La into four- and seven-layer lattices shows that the concentration of PDs required for the transformation of the entire volume of the maternal phase into the $7 \mathrm{R}$ lattice is $1 / 7$, i.e. significantly less than the analogous value $c=1 / 4$, which causes the transformation of $\beta$-La into the low-temperature equilibrium $\alpha$-La polytype. This fact is the main reason that facilitates the formation of a metastable $\mu$-La structure instead of the equilibrium $\alpha$-modification upon rapid cooling of the melt. If the critical level of the parameter $c_{\mathrm{k}}=1 / 7$ is not reached under real conditions of the QLS, or the packing defects are not strictly periodic, then the f.c.c. $\rightarrow 7 \mathrm{R}$ transformation is experienced only by a certain fraction of the volume of the base phase. As a result, a two-phase state $(\beta-\mathrm{La}+\mu$-La) is recorded in the structure of rapidly quenched samples, which is confirmed by the results of $\mathrm{X}$ ray phase analysis.

In $[9,10]$, a mathematical model of the crystallization kinetics of metastable polytypes of cerium and neodymium under nonequilibrium conditions of the QLS is proposed. This model is implemented by means of an agreed numerical solution of the thermal and kinetic tasks for

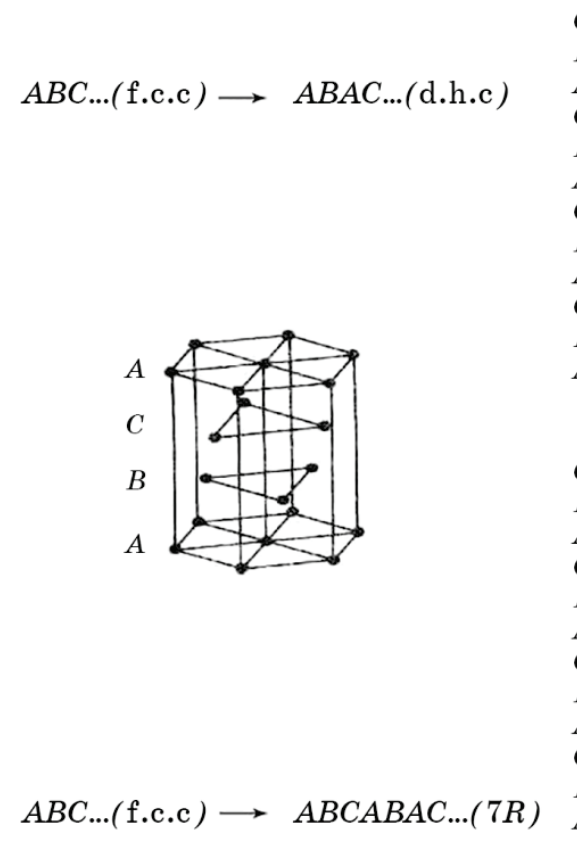

$A$

A

$A$

$A$

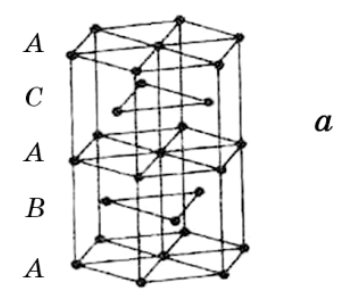

A

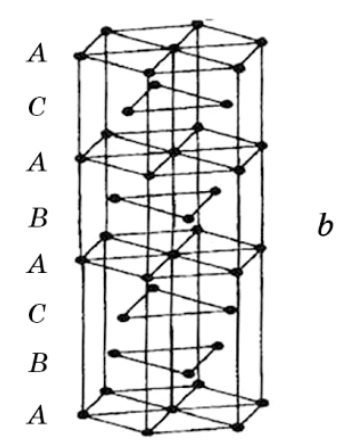

Fig. 1. Mechanism of rearrangement of the basic $\beta$-modification of the La with f.c.c. lattice into lattices of equilibrium (d.h.c., $\alpha$-La) $(a)$ and metastable (7R, $\mu$-La) (b) polytypes. 
thin layers of the melt solidifying on a massive quenching block [11]. Its important advantage is the possibility of its application to complex processes in which several crystalline phases and different transformation mechanisms compete. This possibility is provided by the approximation [12], according to which the processes of crystals nucleation and growth occurs at effective rates proportional to the volume fraction of the maternal phase.

The key element of the kinetic model $[9,10]$ is the probability factor $q_{\mu}$ of transformation of equilibrium close-packed modifications ( $\gamma$-Ce, f.c.c. and $\alpha-\mathrm{Nd}$, d.h.c.) into seven-layer $7 \mathrm{R}$-structures inherent in metastable $\mu$-polytypes. In the cited publications, the value $q_{\mu}$ is associated with the relative thickness $l / l_{\mathrm{k}}$ of rapidly quenched products, using an exponential dependence of the form $\exp \left(-l / l_{\mathrm{k}}\right)$, where $l_{\mathrm{k}}$ is the experimentally determined critical thickness $(60-80) \mu \mathrm{m}$, the excess of which makes the f.c.c. $\rightarrow 7 \mathrm{R}$ and d.h.c. $\rightarrow 7 \mathrm{R}$ transformations unlikely. It is assumed that with an increase in the ratio $l / l_{\mathrm{k}}$, the cooling rate of the melt, the concentration of fixed packing defects, and, consequently, the $q_{\mu}$ value, decrease.

In development of the approach $[9,10]$, this paper presents an improved version of the probabilistic factor $q_{\mu}$, obtained considering the relationships between the rate of the QLS process and the thickness of rapidly quenched samples established in [13]. Using the modified model, a numerical analysis of the competitive crystallization kinetics of lanthanum under the QLS conditions is carried out and an estimate of the degree of metastability of $\mu$-La is obtained.

\section{KINETIC MODEL OF THE METASTABLE LANTHANUM POLYTYPE FORMATION}

The essence of the used model of competitive crystallization of La is illustrated in Fig. 2. It can be seen that, at the stage of nucleation in the supercooled melt L, crystallization centres of two equilibrium modifications of the metal with b.c.c. $(\gamma-\mathrm{La})$ and f.c.c. ( $\beta$-La) lattices are formed. The possibility of alternative nucleation is confirmed by the results of the calculated analysis [11] of the dependences of the reduced supercoolings $\Delta T_{\mathrm{r}}=\left(T_{\mathrm{m}}-T\right) / T_{\mathrm{m}}$ (where $T_{\mathrm{m}}$ is the melting point of lanthanum, $T$ is the current temperature) corresponding to the onset of nucleation processes, on the cooling rate. In particular, it is shown that at $v=5 \cdot 10^{5} \mathrm{~K} / \mathrm{s}$, the first crystalline nuclei in pure metal melts appear at values $\Delta T_{\mathrm{r}}$ equal to 0.125 for $\mathrm{Al}$ and 0.20 for $\mathrm{Ni}$. The given values $\Delta T_{\mathrm{r}}$ are 2.5-4.0 times higher than the relative temperature range of stability of the high-temperature $\gamma$-modification of $\mathrm{La}\left(\Delta T_{\mathrm{r}}=0.05\right.$ [5]). The degree of realization of this possibility is determined by the ratio of the nucleation rates $I_{\gamma}, I_{\beta}$ and its result is the formation of certain amounts $N_{\gamma}, N_{\beta}^{\mathrm{S}}$ of crystallization centres of the competing phases. 
During the growth of crystals from $\gamma$-La nuclei at the rate $u_{\gamma}$ characteristic of this phase, a certain fraction of the converted volume $x_{\gamma}$ is formed. Regarding the centres of crystallization of the f.c.c. $\beta$ modification of La, it is assumed that a certain part $N_{\beta}$ of their total number $N_{\beta}^{\mathrm{S}}$ grows at a rate $u_{\beta}$ with the retention of the basic f.c.c. lattice, forming a fraction of the crystallized volume $x_{\beta}$. The other part $N_{\beta}$ of close-packed nuclei in the process of growth at a rate $u_{\mu}$ undergo a polytypic transformation f.c.c. $\rightarrow 7 \mathrm{R}$, the result of which is the formation of the volume fraction $x_{\mu}$ of the metastable modification. Separation of $\beta$-La nuclei into crystallization centres of two types is carried out in accordance with the probability $q_{\mu}$ of rearrangement of a threelayer (ABC...) lattice of $\beta$-La into a seven-layer (ABCABAC...) lattice $\mu$ $\mathrm{La}$, the cause of which is the saturation of the basic modification with regularly located packing defects of the introduction (Fig. 1, b). Under these assumptions, the number of potential crystallization centres $\mu$ La, and, consequently, the $x_{\mu}$ value is proportional to the probability $q_{\mu}$, while the corresponding indices for the f.c.c. phase $\left(N_{\beta}, x_{\beta}\right)$ vary in proportion to the value $\left(1-q_{\mu}\right)$, which is schematically shown in Fig. 2. It is obvious that the relative contributions of competing equilibrium $(\gamma-\mathrm{La}, \beta-\mathrm{La})$ and metastable ( $\mu$-La) phases to the total fraction of the crystallized volume are related to the fraction of the residual liquid phase $x_{\mathrm{L}}$ by the ratio:

$$
x_{\gamma}+x_{\beta}+x_{\mu}+x_{\mathrm{L}}=1 \text {. }
$$

The values of kinetic variables $x_{\gamma}, x_{\beta}, x_{\mu}$ are calculated within the approximation of effective rates of nucleation and growth of crystals [12] using relations similar to those given in [9] for various modifications of cerium:

$$
\begin{gathered}
x_{\gamma}(t)=\frac{4}{3} \pi \int_{t_{\mathrm{m}}}^{t}\left(1-x\left(t^{\prime}\right)\right) I_{\gamma}\left(t^{\prime}\right)\left[R_{\mathrm{c}}^{\gamma}\left(t^{\prime}\right)+\int_{t^{\prime}}^{t}\left(1-x\left(t^{\prime \prime}\right)\right) u_{\gamma}\left(t^{\prime \prime}\right) d t^{\prime \prime}\right]^{3} d t^{\prime}, \\
x_{\beta}(t)=\frac{4}{3} \pi\left(1-q_{\mu}\right) \int_{t_{\mathrm{m}}}^{t}\left(1-x\left(t^{\prime}\right)\right) I_{\beta}\left(t^{\prime}\right)\left[R_{\mathrm{c}}^{\beta}\left(t^{\prime}\right)+\int_{t^{\prime}}^{t}\left(1-x\left(t^{\prime \prime}\right)\right) u_{\beta}\left(t^{\prime \prime}\right) d t^{\prime \prime}\right]^{3} d t^{\prime}, \\
\underset{I_{\beta}}{\longrightarrow} N_{\beta}^{s} N_{q_{\mu}}^{\stackrel{u_{\gamma}}{\longrightarrow} x_{\gamma}} N_{\mu} \stackrel{u_{\mu}}{\longrightarrow} x_{\mu}
\end{gathered}
$$

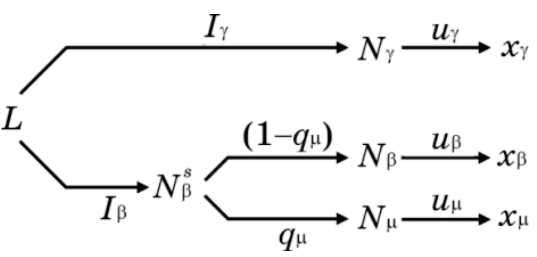

Fig. 2. Scheme of the model of competitive crystallization of lanthanum with the participation of equilibrium $(\gamma, \beta)$ and metastable $(\mu)$ modifications. 


$$
x_{\mu}(t)=\frac{4}{3} \pi q_{\mu} \int_{t_{\mathrm{m}}}^{t}\left(1-x\left(t^{\prime}\right)\right) I_{\beta}\left(t^{\prime}\right)\left[R_{\mathrm{c}}^{\beta}\left(t^{\prime}\right)+\int_{t^{\prime}}^{t}\left(1-x\left(t^{\prime \prime}\right)\right) u_{\mu}\left(t^{\prime \prime}\right) d t^{\prime \prime}\right]^{3} d t^{\prime},
$$

where $R_{\mathrm{c}}^{i}$ is the radius of the crystal nuclei of the critical size for the $i$ modification of La, $t_{\mathrm{m}}$ is the time when the melt reaches the melting point $T_{\mathrm{m}}=1193 \mathrm{~K}$ of lanthanum, $t^{\prime}, t^{\prime \prime}, t$ are current moments of time $\left(t_{\mathrm{m}} \leq t^{\prime} \leq t^{\prime \prime} \leq t_{\mathrm{e}}, t_{\mathrm{e}}\right.$ is the moment of the crystallization process completion), $x=x_{\gamma}+x_{\beta}+x_{\mu}$ is total fraction of the crystallized volume.

To reconciliation of the thermal and kinetic aspects of the competitive crystallization of lanthanum, equations (2)-(4) are solved together with the thermal conductivity equations for melt layers of various thicknesses and a copper quenching block, as well as boundary conditions specifying the thickness of the melt film, the initial temperature of the melt and heat sink, and heat transfer conditions of film with a working environment and a refrigerator. The basis of the mathematical model and the details of the computational algorithm are presented in detail in $[11,14,15]$.

The temperature dependences of the parameters $I_{i}, R_{\mathrm{c}}^{i}, u_{i}$, which, in accordance with Eqs. (2)-(4), control the crystallization kinetics of competing $\gamma_{-}, \beta$ - and $\mu$-phases, are set by the formulas of the classical crystallization theory for the mechanisms of homogeneous nucleation and normal growth of crystals [16, 17]. Calculations of the frequency of formation of crystallization centres under conditions of melt rapid cooling are carried out considering the correction associated with the effect of the nonstationary distribution of heterophase fluctuations size using the method of [18]:

$$
\begin{gathered}
I(T)=I_{0}(T) \exp (-\tau / t), \\
I_{0}(T)=\frac{N_{\mathrm{V}} D(T)}{a_{0}^{2}} \exp \left[-\frac{16}{3} \pi \frac{V^{2} \sigma^{3}}{\Delta G(T) k_{\mathrm{b}} T}\right], \\
\tau=\frac{\pi V^{2} \sigma^{2}}{D(T) \Delta G^{2}(T)}, \\
t=\int_{T}^{T_{\mathrm{m}}} \frac{d T}{v(T)}, \\
R_{\mathrm{c}}(T)=\frac{2 V \sigma}{\Delta G(T)}, \\
u(T)=\frac{f D(T)}{a_{0}}\left[1-\exp \left(-\frac{\Delta G(T)}{R T}\right)\right],
\end{gathered}
$$


where $I_{0}$ is the stationary frequency of nucleation, $\tau$ is settling time of the stationary distribution of density fluctuations, $t$ is the cooling time of the melt from $T_{\mathrm{m}}$ to $T, N_{\mathrm{v}}$ is the number of atoms per unit volume, $D$ is the diffusion coefficient at the crystal-melt interface, $a_{0}$ is the thickness of the interface, $V$ is molar volume, $\sigma$ is the specific free energy of the crystal surface, $\Delta G$ is molar difference of Gibbs free energies between liquid and crystalline phases, $v$ is the current value of the melt cooling rate, $f$ is the fraction of places on the crystals surface in which the attachment of atoms passing from the melt is possible (for metallic materials $f=1$ ), $k_{\mathrm{b}}$ is Boltzmann constant, $R$ is the gas constant.

As follows from Eqs. (6), (7), (9), (10), one of the main factors determining the analysed parameters $I, R_{\mathrm{c}}, u$ is the thermodynamic stimulus $\Delta G$ for crystallization of competing $\gamma-, \beta$ - and $\mu$-modifications of lanthanum. In Figure 3 shows the schematic temperature dependences of the free energies of the liquid and crystalline phases considered in the model. It is seen that, in the temperature range from the melting point $T_{\mathrm{m}}$ to the temperature $T_{\gamma \beta}$ of the polymorphic transformation of $\gamma$-La $\leftrightarrow \beta$-La the thermodynamically most favourable process is the crystallization of the equilibrium high-temperature $\gamma$-modification with a b.c.c. lattice. However, within this interval at temperatures $T_{\gamma \beta}<T<T_{\mathrm{L} \beta}$, the formation of f.c.c. $\beta$-La also becomes possible, since under these temperature conditions $\Delta G_{\mathrm{L} \beta}>0$.

Thus, when the La melt is cooled below $T_{\mathrm{m}}$ the thermodynamic conditions for the non-alternative formation of $\gamma$-La, remain only in a narrow temperature interval $T_{\mathrm{m}}-T_{\mathrm{L} \beta}$, while at lower temperatures $T<T_{\mathrm{L}}$ crystallization acquires the signs of a competitive process, at an early stage of which two equilibrium $\gamma$ - and $\beta$-modifications 'compete'. The real competitiveness of the 'competing' phases is determined by the ratio of the rates of nucleation and growth, the analysis of which will be presented below. In the meantime, let us consider the approximations used in this work for calculating the energy stimulus of crystallization of various phases, as well as two other parameters $(D, \sigma)$ that specify the rates of crystal nucleation and growth.

The difference between the free energies of the melt and the hightemperature $\gamma$-modification of $\mathrm{La} \Delta G_{\mathrm{L} \gamma}$ is calculated on the assumption of linear temperature dependences of the heat capacities of the phases involved in the transformation using the expression:

$$
\Delta G_{\mathrm{L} \gamma}=\frac{\Delta H}{T_{\mathrm{m}}} \Delta T-\Delta a\left(\Delta T-T \ln \frac{T_{\mathrm{m}}}{T}\right)-\frac{\Delta b}{2}(\Delta T)^{2},
$$

where $\Delta H$ is the molar heat of fusion of lanthanum, $\Delta T=T_{\mathrm{m}}-T$ is melt supercooling, $\Delta a, \Delta b$ are the differences of the coefficients that specify the temperature dependences of the heat capacity of the metal in the liquid and solid states. 
The calculations of the energy stimulus of crystallization of the f.c.c. $\beta$-modification of La, which, according to the proposed model, competes with $\gamma$-La at the stage of nucleation, and at the stage of crystal growth, to one degree or another is transformed into a metastable polytype (Fig. 2), are performed according to the relation:

$$
\Delta G_{\mathrm{L} \beta}=\Delta G_{\mathrm{L} \gamma}-\Delta G_{\gamma \beta},
$$

where $\Delta G_{\gamma \beta}=G_{\beta}-G_{\gamma}$ is the difference between the free energies of the $\beta$ and $\gamma$-modifications of La.

As seen from Figure 3, for $T_{\gamma \beta}<T<T_{\mathrm{L} \beta} \Delta G_{\gamma \beta}>0$, and for $T<T_{\gamma \beta}$ $\Delta G_{\gamma \beta}<0$. In turn, the value $\Delta G_{\mathrm{m}}^{\gamma \beta}$ is determined by an equation similar to (11), using the values of the temperature $T_{\gamma \beta}$ and heat $\Delta H_{\gamma \beta}$ of the polymorphic transformation $\gamma$-La $\leftrightarrow \beta$-La, as well as the coefficients $a_{\gamma}$, $b_{\gamma}, a_{\beta}, b_{\beta}$ in the temperature dependences of the heat capacities of $\gamma$ - and $\beta$-modifications of lanthanum.

The thermodynamic stimulus of the $\mu$-La crystal growth process $\Delta G_{\mathrm{L} \mu}$ is calculated assuming that, firstly, the equilibrium $(\beta)$ and metastable $(\mu)$ polytypes are characterized by the identical behaviour of the dependences $\Delta G_{\mathrm{L} \beta}$ and $\Delta G_{\mathrm{L} \mu}$ on supercooling and, secondly, in the entire investigated temperature range, the free energies $\beta$ - and $\mu$-phases differ by some constant value $\Delta G_{\mu \beta}$ (Fig. 3), which is a free parameter of the model. Under these assumptions, the value $\Delta G_{\mathrm{L} \mu}$ can be determined from the calculated values $\Delta G_{\mathrm{L} \beta}$ and a priori the given amendment $\Delta G_{\mu \beta}$ from the ratio:

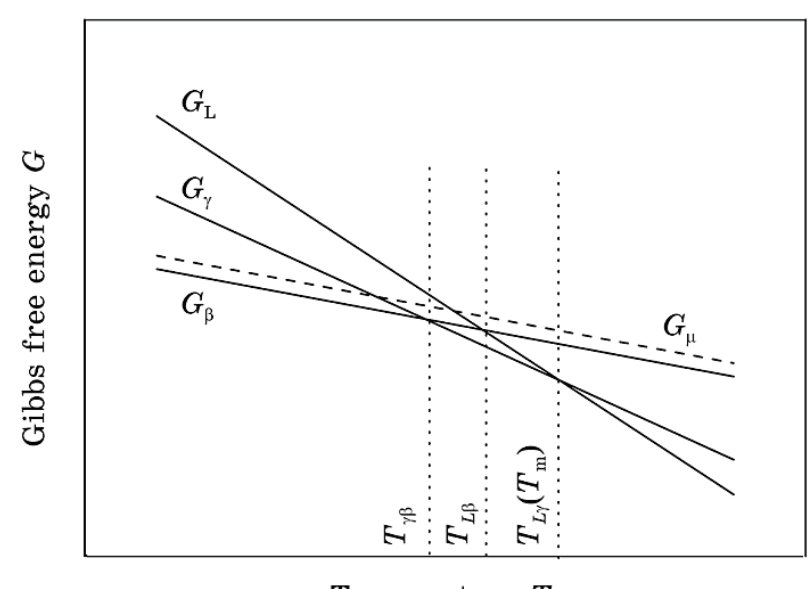

Temperature $T$

Fig. 3. Schematic temperature dependences of the Gibbs free energy for liquid lanthanum $G_{\mathrm{L}}$, as well as equilibrium $G_{\gamma}, G_{\beta}$ and metastable $G_{\mu}$ polymorphic modifications competing in the crystallization process. 


$$
\Delta G_{\mathrm{L} \mu}=\Delta G_{\mathrm{L} \beta}-\Delta G_{\mu \beta} .
$$

The diffusion coefficient $D$ is determined using the Stokes-Einstein equation from the previously calculated values of the viscosity $\eta$ :

$$
D=\frac{k_{\mathrm{b}} T}{3 \pi a_{0} \eta} .
$$

In turn, the temperature dependence of the viscosity is approximated by the empirical Vogel-Fulcher equation [19]:

$$
\eta(T)=A \exp \left(\frac{B}{T-T_{0}}\right),
$$

where $A, B, T_{0}$ are constants, depending on the material nature.

Parameters $A, B, T_{0}$ are determined by solving a system of three equations (15), compiled using reference [20] values of viscosity of lanthanides at two temperatures $T>T_{\mathrm{m}}$ and values $\eta=10^{12} \mathrm{~Pa} \cdot \mathrm{s}$ at a glass transition temperature of lanthanum $T_{\mathrm{g}}=300 \mathrm{~K}$, which is evaluated by the method of work [21].

The values of the specific free energy $\sigma$ at the boundary of the melt with crystals of the $\gamma$ - and $\beta$-modifications of lanthanum are considered independent of temperature and calculated using the formulas proposed by the authors [22] for metals with different types of crystal lattice.

When choosing an expression for the probability of rearrangement of a three-layer f.c.c. lattice of $\beta$-La into a seven-layer 7R lattice of the metastable $\mu$-modification, the sought parameter $q_{\mu}$ is associated with the concentration of packing defects $c$, which can vary from 0 to the critical value $c_{\mathrm{k}}=1 / 7$. In the case $c=0$, the formation of the $\mu$-phase is impossible $\left(q_{\mu}=0\right)$ and the nucleated close-packed crystallization centres grow with the preservation of the f.c.c. lattice of the $\beta$ modification of the metal. If $c=c_{\mathrm{k}}$, then all crystals growing from f.c.c. nuclei acquire crystallographic features of the $\mu$-phase, i.e. $q_{\mu}=1$. The considered interrelationships of the probabilistic factor with the concentration of packing defects can be formalized by the ratio:

$$
q_{\mu}=\frac{c}{c_{\mathrm{k}}} .
$$

Further, it is assumed that the concentration of packing defects is proportional to the rate of the QLS process:

$$
c=k v,
$$

where $k$ is the proportionality coefficient, the value of which is un- 
known.

As shown in [13], the cooling rate is related to the thickness of the melt layer by relations of the form:

$$
\lg v=m-n \lg l \quad \text { or } \quad v=\frac{10^{m}}{l^{n}},
$$

where $m$ and $n$ are constants with different numerical values in three different intervals of $l$.

Hence:

$$
c=k \frac{10^{m}}{l^{n}} .
$$

The value of the coefficient $k$ is determined from the condition that the critical concentration of packing defects $c_{\mathrm{k}}$ is achieved in thin layers $l \leq l_{\mathrm{k}}$, which lies outside the range $(30-80) \mu \mathrm{m}$ used in experiments $[1,2]$. According to the accepted condition, for $l=l_{\mathrm{k}} c=c_{\mathrm{k}}$, whence:

$$
k=c_{\mathrm{k}} \frac{l_{\mathrm{k}}^{n}}{10^{m}} .
$$

By combining Eqs. (16), (19), (20) finally got:

$$
q_{\mu}=\left(\frac{l_{\mathrm{k}}}{l}\right)^{n} .
$$

As can be seen from (21), at $l=l_{\mathrm{k}} q_{\mathrm{u}}=1$. Consequently, all closepacked crystallization centres formed in layers of thickness $l_{\mathrm{k}}$ grow in the form of crystals of the $\mu$-phase. On the other hand, at $l \rightarrow \infty q_{\mu} \rightarrow 0$. This means that the formation of the $\mu$-phase is unlikely in layers with big thickness; in this case, all $\beta$-La nuclei retain the f.c.c. lattice during further growth. For all intermediate values of $l$, the structure of the solidified layers contains $\beta$ - and $\mu$-polytypes of lanthanum, the volume fractions of which are determined by Eqs. (3) and (4).

To remove the ambiguity concerning the concept of 'layers of big thickness', in which the metastable $\mu$-modification of La is not detected experimentally, it is assumed that this condition is fulfilled at values $q_{\mu} \leq 0.05$. The corresponding thickness of the melt layers is determined by plotting the dependences $q_{\mu}(l)$, which are calculated using relation (21) for a number of values $l_{\mathrm{k}}<30 \mu \mathrm{m}$ and a constant $n=2.1$, obtained by averaging the corresponding values for layers with a thickness of 20 to $100 \mu \mathrm{m}$ and thinner $(l<20 \mu \mathrm{m})$ layers [13].

The analysis presented in Fig. 4 plots $q_{\mu}(l)$ leads to the conclusion that the best correlation of the probabilistic factor $q_{\mu}$ with experimental data $[1,2]$ is achieved for the value $l_{\mathrm{k}}=17 \mu \mathrm{m}$. In accordance with this version of the model, the probability of the formation of a 


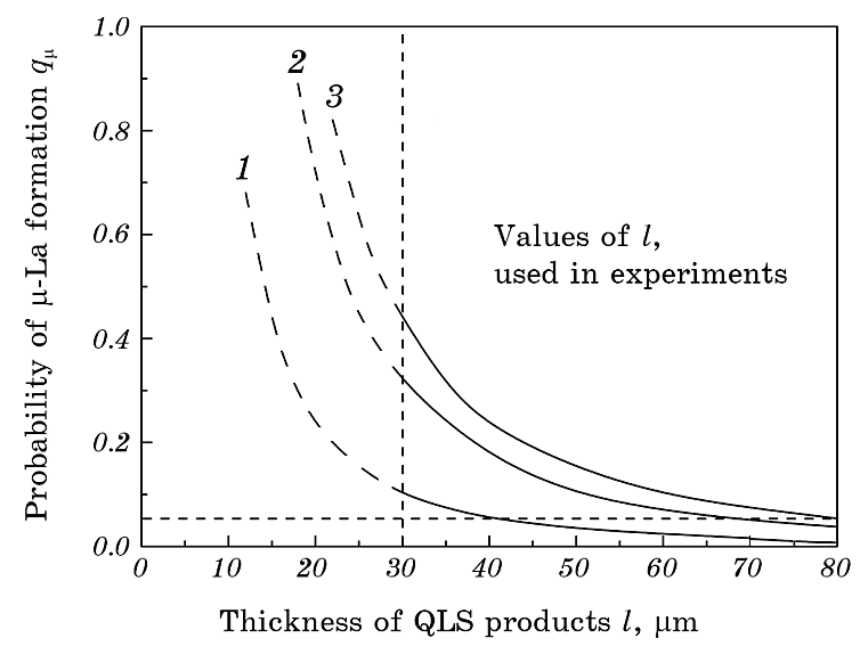

Fig. 4. Dependences of a probability of the metastable lanthanum polytype formation $q_{\mu}$ on the thickness of solidifying layers, calculated by (19) for $l_{\mathrm{k}}$ parameter values equal to $10 \mu \mathrm{m}$ (1), $17 \mu \mathrm{m}$ (2), $20 \mu \mathrm{m}$ (3).

metastable modification of La in quantities sufficient for experimental detection $\left(q_{\mu}>0.05\right)$ is predicted for the products of QLS with a thickness of 30 to $70 \mu \mathrm{m}$. At the lower boundary of this range, the value $q_{\mu}$ is 0.31 . With an increase in the layer thickness $l$, the probability of crystal lattice rearrangement f.c.c. $\rightarrow 7 \mathrm{R}$ decreases, reaching a critical level at $l=70 \mu \mathrm{m}$, which is consistent with the results of X-ray phase analysis $[1,2]$. When the parameter $l_{\mathrm{k}}$ decreases to $10 \mu \mathrm{m}$, the formation of $\mu$-La becomes unlikely (for $l \geq 30 \mu \mathrm{m}, q_{\mu} \leq 0.1$ ). On the contrary, at $l_{\mathrm{k}}=20 \mu \mathrm{m}$, the probability of the formation of the $7 \mathrm{R}$ lattice remains up to the value $l=83 \mu \mathrm{m}$, which goes beyond the range of experimental detection of the $\mu$-polytype. With this in mind, in further calculations we used the value $l_{\mathrm{k}}=17 \mu \mathrm{m}$.

\section{RESULTS OF MODEL CALCULATIONS AND IT'S ANALYSIS}

Figure 5 shows the calculated dependences of the nucleation and growth rates of two equilibrium $\gamma$-and $\beta$-modifications of lanthanum, competing at the stage of formation of crystallization centers, on the reduced supercooling of the melt $\Delta T_{\mathrm{r}}=\left(T_{\mathrm{m}}-T\right) / T_{\mathrm{m}}$. As can be seen from the graphs $I\left(\Delta T_{\mathrm{r}}\right), u\left(\Delta T_{\mathrm{r}}\right)$ in the supercooling range from 0 to $\Delta T_{\mathrm{r}}^{\gamma \beta}=0.049$, the growth rate of the high-temperature b.c.c. $\gamma$ modification of La exceeds the corresponding characteristic of the stable of $\beta$-modification with an f.c.c. lattice at $\Delta T_{\mathrm{r}}>\Delta T_{\mathrm{r}}^{\gamma \beta}$. At the same time, the nucleation processes under real conditions of quenching from the liquid state occur outside the interval $\Delta T_{\mathrm{r}}^{\gamma \beta}$ where the $\gamma$-phase loses 
its advantages in the growth rate and, moreover, is characterized by lower values of the nucleation frequency in comparison with $\beta$-La. In particular, at the moment of reaching the maximum supercooling of the melt, which corresponds to the onset of mass crystallization $\left(x \approx 10^{-2}\right)$ [11], the ratio of the nucleation and growth rates of competing $\gamma$ - and $\beta$-phases for layers with a thickness of $80 \mu \mathrm{m}$ is $I_{\gamma} / I_{\beta}=1,2 \cdot 10^{-7}, u_{\gamma} / u_{\beta}=0.93$.

From the above, it follows that the high-temperature $\gamma$-modification crystallizing from the melt under equilibrium conditions, upon quenching from the liquid state, significantly 'loses' to $\beta$-lanthanum in kinetic terms, primarily in terms of the rate of crystalline nuclei formation. Indeed, according to the obtained calculated data (Fig. 6), the bulk density $N_{\gamma}$ of $\gamma$-La crystals formed in the analyzed range of $l$ $(17-80) \mu \mathrm{m}$ values is negligibly small $\left(N_{\gamma} / N_{\beta}^{\mathrm{S}}<10^{-9}\right)$ in comparison with crystals of competing $\beta$-phase. Shown in Fig. 6 dependencies $N_{\gamma}(l)$ and $N_{\beta}^{\mathrm{S}}(l)$ are a quantitative confirmation of the physical correctness of the model's assumption about the dominant role of $\beta$-La in the formation of primary structure in the conditions of QLS.

In the final block of model calculations, we determined the relative contributions to the converted volume of the high-temperature b.c.c. $\gamma$ modification, as well as the equilibrium $(\beta)$ and metastable $(\mu)$ La polytypes, which, in accordance with the proposed model, are formed at the stage of crystal growth from probabilistically separated f.c.c. nuclei $\beta$ modifications. To analyse the relationship between the thermal regime of the QLS and the crystallization kinetics of competing $\gamma-, \beta$-, and $\mu$ phases, the dependences $T(t), x_{\gamma}(t), x_{\beta}(t)$ and $x_{\mu}(t)$ are calculated.

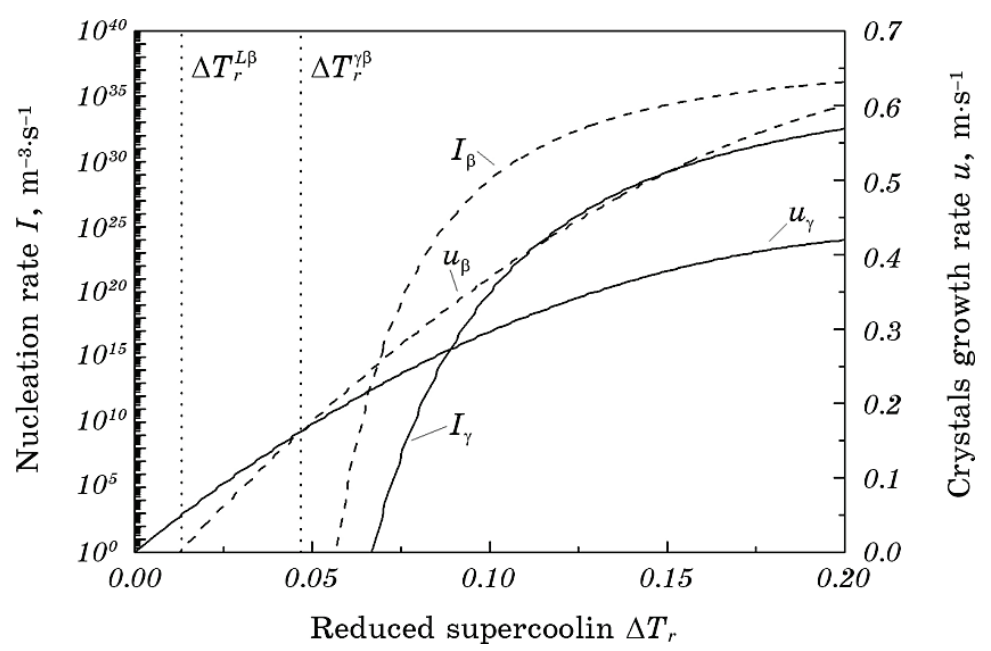

Fig. 5. Dependences of the rates of nucleation $I$ and growth $u$ of crystals of $\gamma$ (solid lines) and $\beta$ - (dashed lines) La modifications on reduced supercooling $\Delta T_{\mathrm{r}}$. 
Calculations are performed for layers, the thickness of which varied from the a priori specified value $l_{\mathrm{k}}=17 \mu \mathrm{m}$ to $80 \mu \mathrm{m}$ and various values $(1-50) \mathrm{J} / \mathrm{mol}$ of the free parameter of the model $\Delta G_{\mu \beta}$. In each version of the calculations, the rate of cooling of the melt $u$ at the melting point of the metal, the maximum supercooling $\Delta T_{\max }$ of the crystallizing layers, and the final values of the relative contributions of each of the analysed phases $\left(x_{\gamma}^{\mathrm{e}}, x_{\beta}^{\mathrm{e}}, x_{\mu}^{\mathrm{e}}\right)$ to the total fraction of the converted volume $x^{\mathrm{e}}$ are determined. The calculation results are summarized in Table 1 and in graphical format are presented in Figs. 7, 8.

According to the data Table 1, with an increase in the thickness of the layers under study, the values of the cooling rate and maximum supercooling of the melt decrease within $\left(7 \cdot 10^{6}-9 \cdot 10^{4}\right) \mathrm{K} / \mathrm{s}$ and $(105-$ $89) \mathrm{K}$, respectively. Nevertheless, in all analysable interval of values $l$ the processes of mass crystallization begin at the temperatures of $T<T_{\gamma \beta}$, i.e. outside the area of thermodynamics stability of $\gamma$-La $\left(\Delta T_{\gamma \beta}=59 \mathrm{~K}\right)$. This increases the competitiveness of $\beta$-La and leads to an almost complete suppression of crystallization of the high-temperature $\gamma$-modification, the final volume fraction of which in the structure of crystallized layers does not exceed $\sim 2 \cdot 10^{-9}$.

The nucleated $\beta$-La crystallization centres, depending on the probability of the formation of packing defects causing the f.c.c. $\rightarrow 7 \mathrm{R}$ polytypic transformation, at the growth stage are separated into crystals of two types (Fig. 2), which make fractional contributions $x_{\beta}$ and $x_{\mu}$ to the converted volume.

A joint analysis of the temperature $T(t)$ and kinetic curves $x_{\beta}(t)$ shown in Fig. 7 for La layers of different thicknesses shows that the

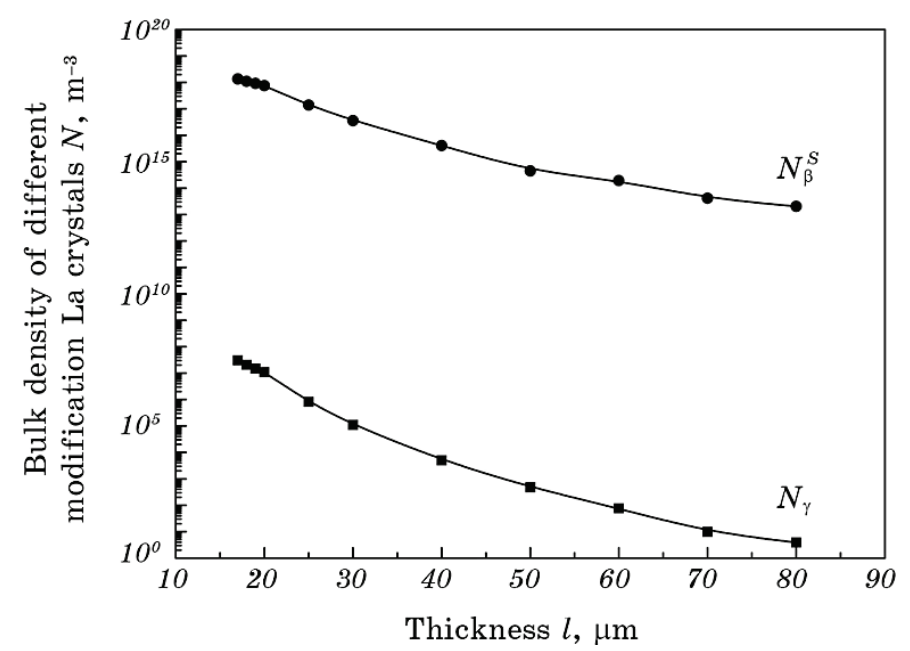

Fig. 6. Change in the bulk density of crystals of $\gamma-\left(N_{\gamma}\right)$ and $\beta$ - $\left(N_{\beta}^{s}\right)$ modifications of La, depending on the thickness of the layers under study. 
TABLE 1. Results of computational analysis of thermal regimes and competitive crystallization kinetics of La layers of different thicknesses for values $l_{\mathrm{k}}=17 \mu \mathrm{m}, \Delta G_{\mu \beta}=5 \mathrm{~J} / \mathrm{mol}$.

\begin{tabular}{|c|c|c|c|c|c|}
\hline \multirow{2}{*}{$\begin{array}{c}\text { Layer } \\
\text { thickness } l, \\
\mu \mathrm{m}\end{array}$} & \multirow{2}{*}{$\begin{array}{c}\text { QLS pro- } \\
\text { cess speed } \\
v \cdot 10^{-5}, \mathrm{~K} / \mathrm{s}\end{array}$} & \multirow{2}{*}{$\begin{array}{l}\text { Maximum super- } \\
\text { cooling of the } \\
\text { melt } \Delta T_{\max }, \mathrm{K}\end{array}$} & \multicolumn{3}{|c|}{$\begin{array}{c}\text { Final volume fractions of competing } \\
\text { La modifications }\end{array}$} \\
\hline & & & $x_{\gamma}^{\mathrm{e}} \cdot 10^{10}$ & $x_{\beta}^{\mathrm{e}} \cdot 10^{2}$ & $x_{\mu}^{\mathrm{e}} \cdot 10^{2}$ \\
\hline 17 & 66 & 104.7 & 20.2 & 0 & 99.9 \\
\hline 18 & 64 & 104.2 & 17.3 & 17.2 & 82.7 \\
\hline 19 & 57 & 103.8 & 15.2 & 30.2 & 69.7 \\
\hline 20 & 52 & 103.4 & 13.5 & 40.2 & 59.7 \\
\hline 25 & 27 & 100.3 & 6.2 & 68.5 & 31.4 \\
\hline 30 & 16 & 98.1 & 3.5 & 80.7 & 19.2 \\
\hline 40 & 6.8 & 94.9 & 1.6 & 90.8 & 9.1 \\
\hline 50 & 3.6 & 92.7 & 0.97 & 94.7 & 5.2 \\
\hline 60 & 2.1 & 91.0 & 0.67 & 96.6 & 3.3 \\
\hline 70 & 1.3 & 89.3 & 0.45 & 97.6 & 2.3 \\
\hline 80 & 0.89 & 88.5 & 0.38 & 98.3 & 1.6 \\
\hline
\end{tabular}

maximum crystallization rate of competing polytypes is achieved in the recalescent regions of the $T(t)$ dependences, which are caused by the self-heating effect of crystallizing layers due to the precipitation of latent heat of transformation. According to the calculation data, a sharp rise in temperature causes a synchronous decrease in the nucleation frequency to such low values that the formation of new crystallization centres ceases. Therefore, at the final stage of the transformation, which occurs under close to isothermal conditions with relatively small melt supercoolings $\left(\Delta T_{\mathrm{r}}=0.015-0.019\right)$, an increase in the volume fractions of $\beta$ - and $\mu$-phases is solely due to the growth of previously nucleated centres.

The change of crystallization mechanism of La thin layers, educed by calculations, reflects on the $x_{\beta}(t)$ and $x_{\mu}(t)$ kinetic dependences as deceleration of increase of parameters $x_{\beta}$ and $x_{\mu}$ (Fig. 7). The effect under consideration is also observed in studies carried out earlier in the relation to pure metals [11] and multicomponent easily amorphizing alloys [23], which makes it possible to classify it as a universal feature of nonequilibrium crystallization of metallic materials under conditions of QLS.

As can be seen from the data Table 1 and graphs $x_{\beta}^{\mathrm{e}}(l), x_{\mu}^{\mathrm{e}}(l)$ shown in Fig. 8, with an increase in the layer thickness within the range from $l_{\mathrm{k}}$ to $80 \mu \mathrm{m}$ used in the calculations, the ratio of the volume fractions of the metastable and equilibrium La polytypes changes in favour of the latter, which is correspond with a decrease in the probability of the $\beta$ $\mathrm{La} \rightarrow \mu$-La transformation determined by (21). At the left boundary of the interval under study $\left(l=l_{\mathrm{k}}\right)$, the structure of $\mu$-La is fixed in the en- 
tire volume of rapidly crystallized samples. As $l$ tends to the maximum value $(80 \mu \mathrm{m}), \beta$-La becomes the dominant structural component. An approximate equality of the values of $x_{\beta}$ and $x_{\mu}$ is achieved in a layer with a thickness of $l_{\mathrm{f}} \approx 21.8 \mu \mathrm{m}$ at the values of the free parameters of the model $l_{\mathrm{k}}=17 \mu \mathrm{m}$ and $\Delta G_{\mu \beta}=5 \mathrm{~J} / \mathrm{mol}$.

The presented results of model calculations agree with the data of $\mathrm{X}$ ray diffraction studies [1,2], which demonstrate a tendency for the volume fraction of the equilibrium $\beta$-polytype of lanthanum to increase with an increase in the thickness of the solidifying layers and indicate that in the diffraction patterns of QLS products with a thickness of more than $70 \mu \mathrm{m}$, the traces of $\mu$-La are not observed.
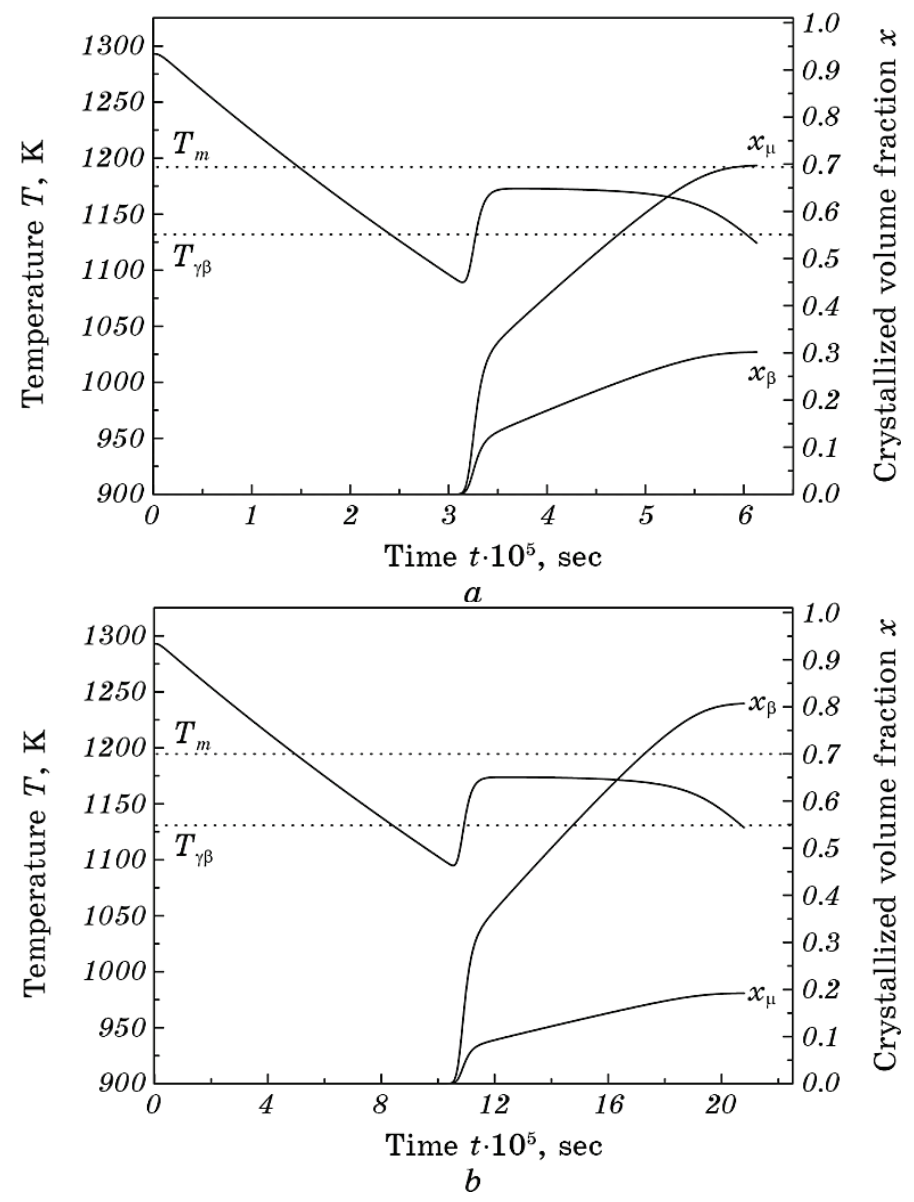

Fig. 7. Graphs of the time variation of the temperature $T(t)$ and the volume fractions of the equilibrium $x_{\beta}(t)$ and metastable $x_{\mu}(t)$ polytypes calculated for crystallizing La layers of thickness $l(\mu \mathrm{m}): 19(a), 30(b), 50(c)$ at model parameter values $l_{\mathrm{k}}=17 \mu \mathrm{m}, \Delta G_{\mu \beta}=5 \mathrm{~J} / \mathrm{mol}$. 


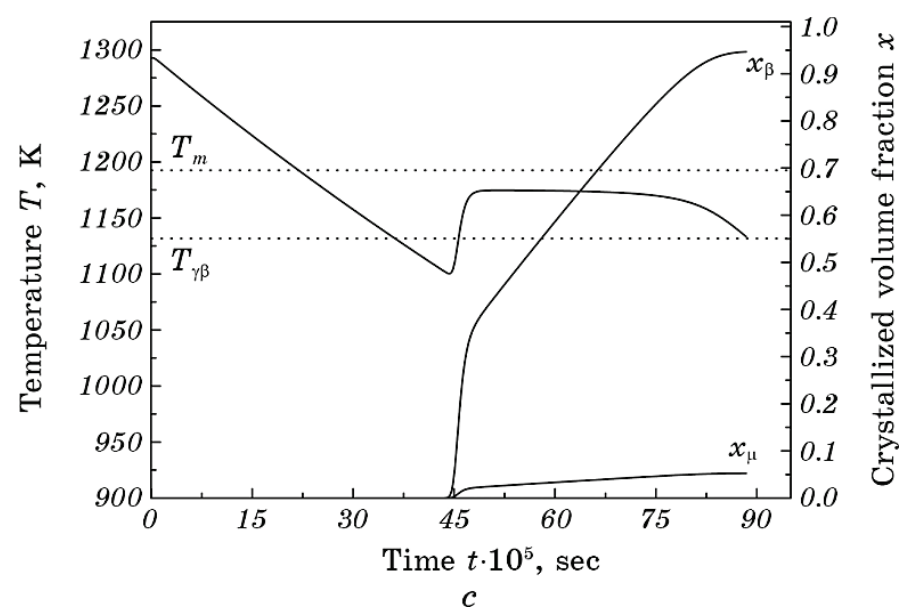

Continuation of Fig. 7.

It is important that the noted correlation of calculations with experiment is achieved at the value of the thermodynamic parameter of the model $\Delta G_{\mu \beta}=5 \mathrm{~J} / \mathrm{mol}$, which is in qualitative agreement with the data [8] regarding relatively low differences of the free energies of different polytypes of metals. This leads to the conclusion about the correctness of the proposed model of competitive crystallization of polymorphic metals and the results of the performed analysis of the kinetics of the formation of the metastable La modification.

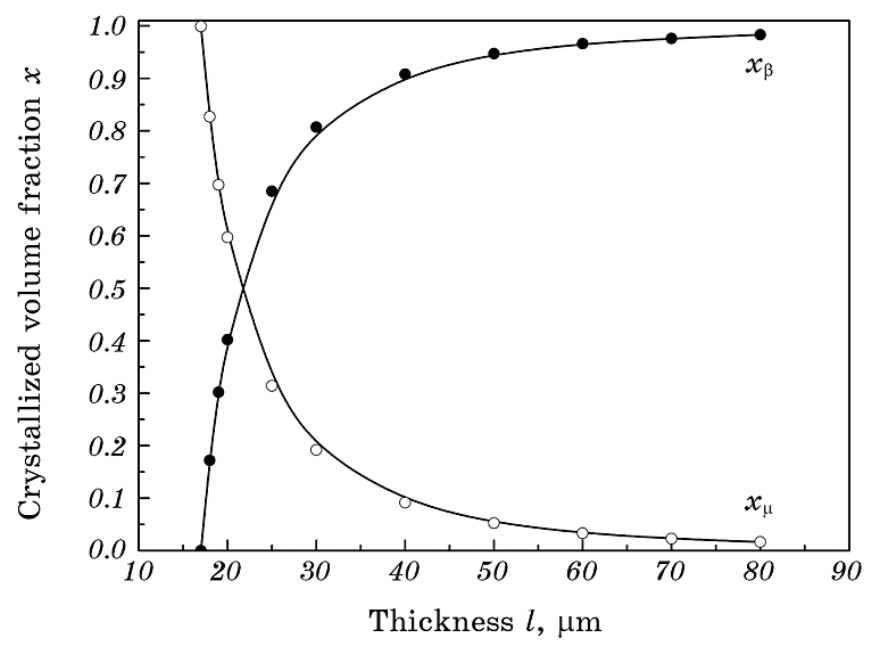

Fig. 8. Dependences of the relative amounts of the equilibrium $\left(x_{\beta}\right)$ and metastable $\left(x_{\mu}\right)$ lanthanum polytypes on the thickness of the rapidly quenched layers $l$, obtained for the values $l_{\mathrm{k}}=17 \mu \mathrm{m}$ and $\Delta G_{\mu \beta}=5 \mathrm{~J} / \mathrm{mol}$. 


\section{CONCLUSIONS}

1. An improved version of the mathematical model of the competitive crystallization of La is proposed, which considers the previously established relationships between the quenching from the liquid state rate and the thickness of the solidifying layers, which increase the physical validity of the expression for the probability of the polytypic transformation of the f.c.c. $\beta$-modification of the metal into the metastable $\mu$-modification with a seven-layer hexagonal lattice.

2 . Using the developed model, a numerical analysis of the crystallization kinetics of thin La melt layers cooled on a copper quenching block is carried out. Actual evidence has been obtained that the f.c.c. $\beta$ modification plays the dominant role in the process of nonequilibrium crystallization, from the nuclei of which, at the growth stage, the crystals of the equilibrium ( $\beta$-La) and metastable ( $\mu$-La) polytypes are formed. The range of values $l=(30-70) \mu \mathrm{m}$ has been determined, within of which the metastable $\mu$-phase is formed in quantities sufficient for X-ray identification.

3. By coordination of the calculated data with the results of X-ray phase analysis of the QLS products a physically correct estimate of the degree of metastability $\mu$-La $\Delta G_{\mu \beta}=5 \mathrm{~J} / \mathrm{mol}$ is obtained.

\section{REFERENCES}

1. A. B. Lysenko, O. L. Kravets, and A. A. Lysenko, Crystallography Reports, 50, No. 1: S10 (2005).

2. A. B. Lysenko, G. V. Borysova, and O. L. Kravets, Fizika i Tekhnika Vysokikh Davlenii, 15, No. 2: 96 (2005) (in Russian).

3. A. B. Lysenko, G. V. Borisova, O. L. Kravets, and A. A. Lysenko, Phys. Met. Metallogr., 101, No. 5: 484 (2006).

4. O. L. Kravets, O. B. Lysenko, G. V. Borysova, and S. L. Revo, Visnyk Kyivskoho universytetu. Fiz.-Mat. Nauky, 4: 353 (2007) (in Ukrainian).

5. E. M. Savickij and V. F. Terehova, Metallovedenie Redkih Metallov [Metallurgy of Rare Metals] (Moscow: Nauka: 1975) (in Russian)

6. I. I. Novikov, Defekty Kristallicheskogo Stroenija Metallov [Defects of the Crystalline Structure of Metals] (Moscow: Metallurgiya: 1975) (in Russian).

7. E. V. Shelehov, N. P. D'jakonova, and T. A. Sviridova, Fiz. Met. Metalloved., 79, No. 3: 121 (1995) (in Russian).

8. B. I. Nikolin, Mnogoslojnye Struktury i Politipizm v Metallicheskih Splavah [Multilayer Structures and Polytypism in Metal Alloys] (Kyiv: Naukova Dumka, 1984) (in Russian)

9. A. B. Lysenko, O. L. Kosinskaja, G. V. Borisova, and T. V. Kalinina, Fiz. Met. Metalloved., 113, No. 6: 620 (2012) (in Russian).

10. A. B. Lysenko, O. L. Kravets, and A. A. Lysenko, Fizika i Tekhnika Vysokikh Davlenii, 19, No. 1: 134 (2009) (in Russian).

11. A. B. Lysenko, G. V. Borisova, O. L. Kravets, and A. A. Lysenko, Fiz. Met. Metalloved., 106, No. 5: 451 (2008) (in Russian). 
12. A. B. Lysenko, Vestnik Dnepropetrouskogo Universiteta. Seriya: Fizika. Radiojelektronika, 18, No. 2: 3 (2011) (in Russian).

13. A. B. Lysenko, G. V. Borisova, and O. L. Kravets, Fizika i Tekhnika Vysokikh Davlenii, 14, No. 1: 44 (2004) (in Russian).

14. A. B. Lysenko, O. L. Kravets, and G. V. Borisova, Fizika i Tekhnika Vysokikh Davlenii, 17, No. 3: 52 (2007) (in Russian).

15. A. B. Lysenko, O. L. Kravets, and A. A. Lysenko, Metallofiz. Noveishie Tekhnol., 30, No. 3: 415 (2008) (in Russian).

16. D. E. Ovsienko, Zarozhdenie i Rost Kristallov iz Rasplava [Nucleation and Growth of Crystals from the Melt] (Kyiv: Naukova Dumka: 1994).

17. A. A. Chernov, Processy Kristallizatsii, Sovremennaya Kristallografiya [Crystallization Processes, Modern Crystallography] (Moscow: Nauka: 1980), vol. 3, p. 7 (in Russian).

18. J. C. A. Wreswijk, R. G. Gossink, and J. M. Stevels, J. Non-Cryst. Solids, 16: 15 (1974).

19. L. Battezzati and A. L. Greer, Acta Metal., 87, No. 7: 1791 (1989).

20. C. I. Smithells, Metally [Metals] (Moscow: Metallurgija: 1987) (in Russian).

21. I. S. Miroshnichenko, Voprosy Formirovanija Metastabil'noj Struktury Splavov [Formation of Metastable Structure of Alloys] (Dnepropetrovsk: 1982), p. 119 (in Russian).

22. M. P. Dohov and S. N. Zadumkin, Smachivaemost' i Poverhnostnye Svojstva Rasplavov i Tverdyh Tel [Wettability and Surface Properties of Melts and Solids] (Kyiv: Naukova Dumka: 1972), p. 18 (in Russian).

23. A. B. Lysenko, O. L. Kosinskaja, S. V. Gubarev, and T. V. Kalinina, Metallofiz. Noveishie Tekhnol., 36, No. 10: 1411 (2014) (in Russian). 